\title{
Aplicação de silício em milho e feijão-de-corda sob estresse salino ${ }^{1}$
}

\author{
Silicon application on plants of maize and cowpea under salt stress
}

\author{
Michella de Albuquerque Lima ${ }^{2}$, Victor Freitas de Castro ${ }^{3}$, Jones Batista Vidal ${ }^{3}$ e Joaquim Enéas-Filho ${ }^{4 *}$
}

\begin{abstract}
Resumo - Apesar de não ser um nutriente essencial, o silício pode aumentar o potencial produtivo de algumas culturas e tem sido utilizado para atenuar os efeitos tóxicos do estresse salino. Nesse sentido, objetivou-se avaliar o efeito do silicato de sódio aplicado sob dois modos diferentes em plântulas de milho e feijão-de-corda submetidas à salinidade. Em casa de vegetação, as plântulas receberam uma dose de $\mathrm{Na}_{2} \mathrm{SiO}_{3}$ a $1 \mathrm{mM}$, via aplicação foliar ou diretamente na solução nutritiva, e foram cultivadas na presença ou ausência de $\mathrm{NaCl}$ a $100 \mathrm{mM}$, durante 15 dias. Foram avaliados a matéria seca de folhas, caules e raízes, a área foliar e o vazamento de eletrólitos em folhas e raízes. De modo geral, a salinidade reduziu a matéria seca das folhas, caules e raízes e aumentou o vazamento de eletrólitos nas folhas e raízes das plântulas. A aplicação de silício via solução nutritiva promoveu maiores valores em todos os parâmetros de crescimento e reduziu os danos de membrana no milho, mas isso não foi observado em feijão-de-corda. O silício atenuou os efeitos tóxicos do $\mathrm{NaCl}$ no crescimento das plântulas de milho, quando aplicado diretamente na solução nutritiva.
\end{abstract}

Palavras-chave - Silicatos. Salinidade. Zea mays. Vigna unguiculata.

\begin{abstract}
Although silicon is not considered an essential nutrient for plants, it can increase the yield potential of some crops and has been used to mitigate the toxic effects of salt stress. The aim of this work was to evaluate the effect of sodium silicate applied in two different ways in maize and cowpea seedlings subjected to salinity. Seedlings were grown in Hoagland solutions and maintained in a greenhouse. Seedlings received $1.0 \mathrm{mM} \mathrm{Na} \mathrm{SiO}_{3}$ applied directly in the nutrient solutions or by foliar supply, and they were subjected to $100 \mathrm{mM} \mathrm{NaCl}$ for 15 days. We evaluated the dry weight of leaves, stems and roots, leaf area and ion leakage in leaves and roots. Salinity reduced dry weight of leaves, stems and roots and increased leaves and root ion leakage. Silicon application in the nutrient solution significantly increased all growth parameters and decreased ion leakage in maize seedlings, whereas this response was not observed in cowpea. Silicon was able to relieve the toxic effects of $\mathrm{NaCl}$ on growth only in maize seedlings when applied directly in the nutrient solution.
\end{abstract}

Key words - Silicates. Salinity. Zea mays. Vigna unguiculata.

\footnotetext{
* Autor para correspondência

'Recebido para publicação em 31/08/2010; aprovado em 31/01/2011

Trabalho submetido e selecionado no primeiro Simpósio Brasileiro de Salinidade realizado de 12-15/10/2010 em Fortaleza, Ceará, Brasil; Texto extraído da Tese de Doutorado do primeiro autor, pesquisa financiada pelo $\mathrm{CNPq}$

2Programa de Pós-Graduação em Agronomia/Fitotecnia, Fortaleza-CE, Brasil, 60.455-970, michella_bio@yahoo.com.br

${ }^{3}$ Graduando em Agronomia, Departamento de Agronomia/Fitotecnia, Universidade Federal do Ceará, Av. Humberto Monte, S/N, Campus do Pici,

Fortaleza-CE, Brasil,60.455-970,jbv_89@yahoo.com.br, vfreitascastro@yahoo.com.br

${ }^{4}$ Departamento de Bioquímica de Biologia Molecular, Universidade Federal do Ceará, Fortaleza-CE, Brasil, 60.455-970, joaquime@ufc.br
} 


\section{Introdução}

A salinidade é um dos principais fatores abióticos que contribuem para a diminuição da produtividade das plantas. Este fator é mais expressivo nas regiões áridas e semiáridas, as quais apresentam grandes contrastes ambientais (PARIDA; DAS, 2004). As principais causas dos processos de salinização das áreas agricultáveis nestas regiões são decorrentes da baixa precipitação pluviométrica, alta evaporação, material de origem dos solos, irrigação mal conduzida, além de drenagem inadequada (DANTAS et al., 2006). O estresse salino compromete o crescimento da planta por baixar o potencial osmótico da solução do solo, causando estresse hídrico e provocando efeitos tóxicos nas plantas que resultam em injúrias no metabolismo e desordens nutricionais (ALVES, 2009; DEBOUBA et al., 2006; MUNNS; TESTER, 2008).

Mesmo não sendo considerado um elemento essencial para o crescimento e desenvolvimento das plantas, o silício tem sido associado a diversos efeitos benéficos, dentre os quais se destacam: o baixo coeficiente de transpiração, com melhor aproveitamento da água; o maior teor de clorofila e a maior rigidez estrutural dos tecidos, com o aumento da resistência mecânica das células, deixando as folhas mais eretas e aumentando a área fotossintética e a absorção de $\mathrm{CO}_{2}$. Somam-se a isto, a diminuição do autossombreamento e a redução do acamamento; o aumento do número de folhas e da matéria seca; o retardo da senescência e a proteção contra estresses bióticos, através da diminuição da incidência de patógenos e do aumento da resistência a insetos pela formação de uma barreira mecânica. Também está envolvido na tolerância a estresses abióticos, como o salino, tornando as células mais tolerantes (EPSTEIN, 1999). Esses fatores fizeram com que, no Brasil, o silício passasse a fazer parte da lista de micronutrientes, embora as pesquisas ainda não tenham demonstrado a essencialidade deste elemento (OLIVEIRA, 2009).

O composto de silício presente na fase líquida do solo, na faixa de pH entre 4 e 9, é o monômero $\mathrm{H}_{4} \mathrm{SiO}_{4}$ (MARSCHNER, 1995), o qual é absorvido pelas raízes das plantas na forma passiva ou ativa por transportadores de membrana específicos para este fim. Entretanto, as espécies vegetais variam grandemente em sua capacidade de absorver e acumular silício nos tecidos, podendo, em função dos percentuais de $\mathrm{SiO}_{2}$ na matéria seca da parte aérea, serem classificadas como: a) plantas acumuladoras, que incluem muitas gramíneas, como o arroz, contendo acima de $4 \%$ de $\mathrm{SiO}_{2}$; b) intermediárias, com teores de $\mathrm{SiO}_{2}$ variando entre 2-4\% (cereais, cana-de-açúcar e poucas dicotiledôneas); c) plantas não acumuladoras, incluindo a maioria das dicotiledôneas, apresentando valores menores que $2 \%$ de $\mathrm{SiO}_{2}$, como feijão (MA; TAKAHASHI, 2002; HODSON et al., 2005). Essas diferenças na acumulação de silício têm sido atribuídas à habilidade das raízes em absorver esse nutriente (TAKAHASHI et al., 1990), mas o mecanismo exato envolvido exatamente ainda não é bem compreendido.

O emprego do Si na redução da toxidez causada pelo excesso de $\mathrm{NaCl}$ foi proposto por Ahmad (1992), que conseguiu resultados positivos na produção de matéria seca em trigo (Triticum vulgare) tratado com esse elemento e submetido à salinidade. Outros autores também demonstraram efeito semelhante em algaroba (Prosopis juliflora) (BRADBURY; AHMAD, 1990), cajueiro (Anacardium occidentale) e moringa (Moringa oleifera) (MIRANDA, 2002).

Assim, este trabalho teve por objetivo avaliar a capacidade do silício de atenuar os efeitos da salinidade em plântulas de milho e feijão-de-corda, relacionando-a com o seu modo de aplicação.

\section{Material e métodos}

\section{Condições de crescimento}

A fase de germinação e o desenvolvimento inicial das plântulas foram conduzidos em casa de vegetação do Departamento de Bioquímica e Biologia Molecular, da Universidade Federal do Ceará, situada no campus do Pici, Fortaleza, Ceará, Brasil (latitude $3^{\circ} 44^{\prime}$ S, longitude $38^{\circ} 34^{\prime}$ W), temperatura de 29 a $38^{\circ} \mathrm{C}$ durante o dia, e de 26 a $28^{\circ} \mathrm{C}$ durante a noite e umidade relativa de 50 a $82 \%$ (dia/noite). A radiação fotossintética ativa máxima nas proximidades das folhas foi aproximadamente de $1.200 \mu \mathrm{mol} \mathrm{m} \mathrm{m}^{-2} \mathrm{~s}^{-1}$, mensurada utilizando-se um analisador portátil de gás no infravermelho - IRGA (modelo LCi, ADC BioScientific, Inglaterra), em sistema aberto, sob luz saturante e condições ambientes de temperatura e concentração de $\mathrm{CO}_{2}$.

\section{Cultivo das plantas e tratamentos}

Sementes de feijão-de-corda (Vigna unguiculata), cv Pitiúba, e de milho (Zea mays), cv BRS 3003, foram esterilizadas com solução de $\mathrm{NaClO}$ (1:3; v:v) e lavadas com água destilada. Posteriormente, foram semeadas em papel germitest contendo solução nutritiva de Hoagland e Arnon (1950) a 50\% de sua concentração original. Cinco dias após a semeadura, as plântulas foram transplantadas para vasos de $3 \mathrm{~L}$ contendo a mesma solução nutritiva e, após dois dias de aclimatação, deu-se início ao tratamento com $\mathrm{NaCl}$ e $\mathrm{Na}_{2} \mathrm{SiO}_{3}$.

As aplicações, tanto foliar como na solução nutritiva, foram feitas em doses diárias de $0,2 \mathrm{mM}$ de 
$\mathrm{Na}_{2} \mathrm{SiO}_{3}$, durante cinco dias. As fertilizações foram realizadas sempre às $17 \mathrm{~h}$, com o objetivo de minimizar as possíveis perdas provocadas pela volatilização. Para garantir a melhor aderência do silicato durante a aplicação foliar, utilizou-se Tween-20 a $0,025 \%$. A solução foi trocada a cada cinco dias e o $\mathrm{pH}$ ajustado para 6,0 sempre que necessário.

\section{Obtenção de matéria seca e área foliar}

Ao completarem 15 dias da adição de $\mathrm{NaCl}$, as plantas foram coletadas e a área foliar foi medida em aparelho tipo LI-3100 (Area meter, Li-Cor, Inc. Lincoln, Nebraska, USA). Em seguida, as plantas foram separadas em folhas, caules e raízes, pesadas e colocadas em estufa de circulação de ar a $60^{\circ} \mathrm{C}$, por três dias, para a determinação da matéria seca de cada órgão.

\section{Integridade das membranas}

O grau de integridade das membranas foi estimado pelo vazamento de eletrólitos. Amostras de $100 \mathrm{mg}$ de discos foliares e de raízes de cada tratamento foram expostas a $10 \mathrm{~mL}$ de água desionizada durante duas horas. Em seguida, a condutividade elétrica $\left(\mu \mathrm{S} \mathrm{m}^{-1}\right)$ do extrato (L1) foi determinada em condutivímetro (Analyser, mod. 650, São Paulo, Brasil) e os mesmos segmentos de raízes e folhas foram colocadas novamente em água fervente, por $1 \mathrm{~h}$. Após alcançada a temperatura ambiente, fez-se uma leitura (L2) da condutividade elétrica final $\left(\mu \mathrm{S} \mathrm{m}^{-1}\right)$ do extrato. O percentual de danos das membranas (\%DM) das folhas (DMF) e das raízes (DMR) foi estabelecido pela seguinte relação: \%DM $=(\mathrm{L} 1 / \mathrm{L} 2)$ x 100 .

\section{Delineamento estatístico e análise dos resultados}

$\mathrm{O}$ delineamento experimental foi inteiramente casualizado, em arranjo fatorial $2 \times 2 \times 2$, sendo utilizados dois níveis de $\mathrm{NaCl}(0$ e $100 \mathrm{mM})$, dois níveis de silicato de sódio $(0$ e $1 \mathrm{mM})$ e duas formas de aplicação do silício (por via foliar e diretamente na solução nutritiva), com cinco repetições, sendo utilizadas duas plântulas de cada espécie por repetição. Os dados foram submetidos à análise de variância e a comparação de médias foi obtida pela aplicação do teste de Tukey a $5 \%$ de significância.

\section{Resultados e discussão}

Pelos resultados da Tabela 1, constata-se que a salinidade do cloreto de sódio inibiu significativamente $(\mathrm{p}<0,05)$ a produção de massa seca das raízes (MSR), folhas (MSF) e do colmo (MSC), bem como a área foliar (AF) das plantas, independentemente do modo de aplicação de silício e em ambas as culturas. A tendência dos resultados está em acordo com Tahir et al. (2006) que observaram efeitos negativos do $\mathrm{NaCl}$ no crescimento de plantas de trigo. Segundo Lacerda (2005) e Munns (2002), essa redução do crescimento das plantas submetidas ao cloreto de sódio em solução nutritiva é resposta ao efeito osmótico, associado à toxicidade causada pela absorção excessiva de $\mathrm{Na}^{+} \mathrm{e} \mathrm{Cl}^{-}$ e ao desequilíbrio nutricional causado pelos distúrbios na absorção ou distribuição desses nutrientes nos distintos órgãos das respectivas plantas.

Apesar dos menores valores em relação ao tratamento controle, a aplicação de $\mathrm{Na}_{2} \mathrm{SiO}_{3}$ diretamente na solução nutritiva foi capaz de influenciar a matéria seca dos órgãos e a área foliar das plântulas de milho, sendo este último a espécie mais beneficiada. Por outro lado, quando aplicado via foliar, o $\mathrm{Na}_{2} \mathrm{SiO}_{3}$ não exerceu efeitos positivos nos parâmetros de crescimento de ambas as plântulas. A absorção provavelmente se deu de forma mais eficaz nas plântulas de milho (gramíneas) consideradas acumuladoras de silício (MA et al., 2001). Devido ao fato de o feijão não ser uma gramínea e esta cultura ser considerada não acumuladora de silício, não foram observadas respostas quanto à aplicação desse elemento.

Segundo Silveira et al. (2005), o crescimento, a produtividade e o estado nutricional do feijoeiro são afetados por um grande número de fatores, destacandose as adubações realizadas. Outra possível causa dessa resposta negativa do feijoeiro pode estar relacionada à dose de silício aplicada que pode não ter sido suficiente para sua absorção. Franzote et al. (2005), em um estudo com plântulas de feijão, cv BRS-MG Talismã, sob aplicação foliar de um fertilizante comercial contendo $21 \%$ de silício em doses crescentes $(0 ; 4,25 ; 8,50 ; 12,75$ e $17 \mathrm{ppm}$ ), observaram que, nas doses empregadas, este nutriente não influenciou no crescimento e no rendimento de grãos do feijoeiro. Segundo os autores, estes resultados indicam que a dose de resposta do feijoeiro pode estar além do espaço experimental empregado, já que a dose máxima empregada foi de apenas 17 ppm.

$\mathrm{Na}$ Tabela 2, estão apresentados os valores médios dos danos de membrana nas raízes e nas folhas. Verificou-se que não houve efeito da aplicação foliar do silício nestas avaliações, tanto para as plântulas de milho como para as de feijão. Entretanto, quando a aplicação foi na solução nutritiva, obteve-se um menor dano nas folhas e raízes das plântulas de milho. A aplicação de $\mathrm{Na}_{2} \mathrm{SiO}_{3}$ diretamente na solução nutritiva reduziu o vazamento de eletrólitos em $11,78 \%$ nas raízes e $25,08 \%$ em folhas de plântulas de milho. 
Tabela 1 - Matéria seca das folhas (MSF), dos caules (MSC) e das raízes (MSR) e área foliar (AF) de plântulas de milho e feijão-de-corda cultivadas sob condições salinas e não salinas, sob aplicação de $\mathrm{Na}_{2} \mathrm{SiO}_{3}$ via foliar e na solução nutritiva

\begin{tabular}{|c|c|c|c|c|c|}
\hline \multirow{2}{*}{ Tratamento } & \multirow{2}{*}{ Conc. (mM) } & MSF & MSC & MSR & \multirow{2}{*}{$\mathrm{AF}\left(\mathrm{cm}^{2}\right)$} \\
\hline & & \multicolumn{3}{|c|}{ g planta ${ }^{-1}$} & \\
\hline \multicolumn{6}{|c|}{ MILHO } \\
\hline \multicolumn{6}{|l|}{ Foliar } \\
\hline $\mathrm{Na}_{2} \mathrm{SiO}_{3}+\mathrm{NaCl}$ & $0 / 0$ & $0,1387 \pm 0,120 \mathrm{a}$ & $0,465 \pm 0,104 \mathrm{a}$ & $0,099 \pm 0,023 \mathrm{~b}$ & $250,66 \pm 5,430 \mathrm{a}$ \\
\hline $\mathrm{Na}_{2} \mathrm{SiO}_{3}+\mathrm{NaCl}$ & $1 / 0$ & $0,1456 \pm 0,276 \mathrm{a}$ & $0,576 \pm 0,168 \mathrm{a}$ & $0,101 \pm 0,065 \mathrm{~b}$ & $255,85 \pm 6,765 \mathrm{a}$ \\
\hline $\mathrm{Na}_{2} \mathrm{SiO}_{3}+\mathrm{NaCl}$ & $0 / 100$ & $0,984 \pm 0,211 \mathrm{~b}$ & $0,300 \pm 0,076 \mathrm{~b}$ & $0,209 \pm 0,056 \mathrm{a}$ & $188,01 \pm 4,765 b$ \\
\hline $\mathrm{Na}_{2} \mathrm{SiO}_{3}+\mathrm{NaCl}$ & $1 / 100$ & $0,972 \pm 0,145 \mathrm{~b}$ & $0,322 \pm 0,650 \mathrm{~b}$ & $0,190 \pm 0,085 \mathrm{a}$ & $190,65 \pm 4,654 b$ \\
\hline \multicolumn{6}{|l|}{ Direta } \\
\hline $\mathrm{Na}_{2} \mathrm{SiO}_{3}+\mathrm{NaCl}$ & $0 / 0$ & $1,264 \pm 0,182 \mathrm{~b}$ & $0,539 \pm 0,104 \mathrm{~b}$ & $0,154 \pm 0,046 \mathrm{~d}$ & $290,98 \pm 8,034 \mathrm{a}$ \\
\hline $\mathrm{Na}_{2} \mathrm{SiO}_{3}+\mathrm{NaCl}$ & $1 / 0$ & $1,445 \pm 0,104 \mathrm{a}$ & $0,785 \pm 0,168 \mathrm{a}$ & $0,186 \pm 0,038 \mathrm{c}$ & $291,93 \pm 7,981 \mathrm{a}$ \\
\hline $\mathrm{Na}_{2} \mathrm{SiO}_{3}+\mathrm{NaCl}$ & $0 / 100$ & $0,777 \pm 0,218 \mathrm{~d}$ & $0,365 \pm 0,085 \mathrm{~b}$ & $0,209 \pm 0,035 \mathrm{a}$ & $174,02 \pm 9,594 \mathrm{c}$ \\
\hline $\mathrm{Na}_{2} \mathrm{SiO}_{3}+\mathrm{NaCl}$ & $1 / 100$ & $0,951 \pm 0,121 \mathrm{c}$ & $0,522 \pm 0,101 \mathrm{c}$ & $0,190 \pm 0,073 \mathrm{~b}$ & $202,36 \pm 4,822 b$ \\
\hline \multicolumn{6}{|c|}{ FEIJÃO } \\
\hline \multicolumn{6}{|l|}{ Foliar } \\
\hline $\mathrm{Na}_{2} \mathrm{SiO}_{3}+\mathrm{NaCl}$ & $0 / 0$ & $1,39 \pm 0,011 \mathrm{a}$ & $1,12 \pm 0,053 \mathrm{a}$ & $1,05 \pm 0,020 \mathrm{a}$ & $1,05 \pm 0,020 \mathrm{a}$ \\
\hline $\mathrm{Na}_{2} \mathrm{SiO}_{3}+\mathrm{NaCl}$ & $1 / 0$ & $1,41 \pm 0,008 \mathrm{a}$ & $1,10 \pm 0,048 \mathrm{a}$ & $1,04 \pm 0,039 \mathrm{a}$ & $1,04 \pm 0,039 \mathrm{a}$ \\
\hline $\mathrm{Na}_{2} \mathrm{SiO}_{3}+\mathrm{NaCl}$ & $0 / 100$ & $1,20 \pm 0,015 b$ & $0,85 \pm 0,064 \mathrm{~b}$ & $0,78 \pm 0,033 \mathrm{~b}$ & $0,89 \pm 0,033 \mathrm{~b}$ \\
\hline $\mathrm{Na}_{2} \mathrm{SiO}_{3}+\mathrm{NaCl}$ & $1 / 100$ & $1,19 \pm 0,009 \mathrm{~b}$ & $0,88 \pm 0,118 \mathrm{~b}$ & $0,76 \pm 0,025 \mathrm{~b}$ & $0,88 \pm 0,025 \mathrm{~b}$ \\
\hline \multicolumn{6}{|l|}{ Direta } \\
\hline $\mathrm{Na}_{2} \mathrm{SiO}_{3}+\mathrm{NaCl}$ & $0 / 0$ & $1,100 \pm 0,022 \mathrm{a}$ & $0,469 \pm 0,87 \mathrm{a}$ & $0,134 \pm 0,057 \mathrm{~b}$ & $250,81 \pm 0,87 \mathrm{a}$ \\
\hline $\mathrm{Na}_{2} \mathrm{SiO}_{3}+\mathrm{NaCl}$ & $1 / 0$ & $1,110 \pm 0,023 \mathrm{a}$ & $0,435 \pm 0,78 \mathrm{a}$ & $0,196 \pm 0,055 \mathrm{a}$ & $251,45 \pm 0,56 \mathrm{a}$ \\
\hline $\mathrm{Na}_{2} \mathrm{SiO}_{3}+\mathrm{NaCl}$ & $0 / 100$ & $0,887 \pm 0,043 \mathrm{~b}$ & $0,330 \pm 0,063 \mathrm{~b}$ & $0,88 \pm 0,043 \mathrm{c}$ & $163,54 \pm 0,87 \mathrm{c}$ \\
\hline $\mathrm{Na}_{2} \mathrm{SiO}_{3}+\mathrm{NaCl}$ & $1 / 100$ & $0,895 \pm 0,036 \mathrm{~b}$ & $0,299 \pm 0,102 \mathrm{~b}$ & $0,87 \pm 0,054 \mathrm{c}$ & $171,76 \pm 0,88 \mathrm{~b}$ \\
\hline
\end{tabular}

Letras iguais na mesma coluna não representam diferenças significativas pelo teste de Tukey ao nível de significância de 5\%

O comportamento dos dados assemelham-se aos apresentado por Al-Aghabary et al. (2004) que observaram aumentos na produção de matéria seca de 19,$5 ; 25,4 ; 13,4$ e $21,2 \%$ em folhas, colmo, raízes e total, respectivamente, em tomate (Lycopersicon esculentum Mill. cv Hong mei) sob condições de $\mathrm{NaCl}$ a $100 \mathrm{mM}$, com aplicação de $2,5 \mathrm{mM}$ de $\mathrm{Na}_{2} \mathrm{SiO}_{3}$.

A aplicação de $\mathrm{Na}_{2} \mathrm{SiO}_{3}$ na solução nutritiva parece ser a forma mais viável devido à maneira como este nutriente é absorvido em algumas plantas. Possivelmente, a adição de silício via foliar pode não ter sido eficaz para absorção desse nutriente por esta não ser a via de entrada mais adequada. Mitani et al. (2009) identificaram dois genes de transportadores de silício presentes em milho (ZmLsil e ZmLsiø). O ZmLsil é mais expressivo em raízes, enquanto que ZmLsi6 ocorre mais em folhas. É possível que os transportadores sejam mais expressos nas raízes do que nas folhas, tanto nas cultivares de milho como nas de feijão-de-corda, o que poderia explicar a não obtenção de uma resposta benéfica do silício via aplicação foliar.

Outro fator a ser observado é que a concentração de silício aplicada pode não ter sido suficiente para sua absorção nas folhas, enquanto ela o foi para as raízes. Em estudo com um híbrido simples de milho, Freitas et al. (2008), utilizando dosagens crescentes de silício por adubação foliar, verificaram que não houve acúmulo desse 
Tabela 2 - Valores médios dos danos de membranas das raízes (DMR) e folhas (DMF) de plântulas de milho e feijão-de-corda, cultivados sob condições salinas e não salinas sob aplicação de $\mathrm{Na}_{2} \mathrm{SiO}_{3}$ via foliar e na solução nutritiva

\begin{tabular}{|c|c|c|c|}
\hline \multirow{2}{*}{ Tratamento } & \multirow{2}{*}{ Conc. (mM) } & DMR & DMF \\
\hline & & \multicolumn{2}{|c|}{$\%$} \\
\hline \multicolumn{4}{|c|}{ MILHO } \\
\hline \multicolumn{4}{|l|}{ Foliar } \\
\hline $\mathrm{Na}_{2} \mathrm{SiO}_{3}+\mathrm{NaCl}$ & $0 / 0$ & $40,332 \pm 0,44 \mathrm{c}$ & $21,652 \pm 0,86 b$ \\
\hline $\mathrm{Na}_{2} \mathrm{SiO}_{3}+\mathrm{NaCl}$ & $1 / 0$ & $39,87 \pm 0,42 \mathrm{c}$ & $22,157 \pm 1,94 b$ \\
\hline $\mathrm{Na}_{2} \mathrm{SiO}_{3}+\mathrm{NaCl}$ & $0 / 100$ & $47,71 \pm 1,16 \mathrm{a}$ & $39,162 \pm 0,48 \mathrm{a}$ \\
\hline $\mathrm{Na}_{2} \mathrm{SiO}_{3}+\mathrm{NaCl}$ & $1 / 100$ & $48,43 \pm 0,33 \mathrm{a}$ & $37,707 \pm 0,20 \mathrm{a}$ \\
\hline \multicolumn{4}{|l|}{ Direta } \\
\hline $\mathrm{Na}_{2} \mathrm{SiO}_{3}+\mathrm{NaCl}$ & $0 / 0$ & $55,406 \pm 1,59 \mathrm{c}$ & $26,987 \pm 0,19 c$ \\
\hline $\mathrm{Na}_{2} \mathrm{SiO}_{3}+\mathrm{NaCl}$ & $1 / 0$ & $49,567 \pm 1,34 \mathrm{~d}$ & $23,109 \pm 0,73 \mathrm{~d}$ \\
\hline $\mathrm{Na}_{2} \mathrm{SiO}_{3}+\mathrm{NaCl}$ & $0 / 100$ & $76,596 \pm 0,67 \mathrm{a}$ & $45,745 \pm 0,90 \mathrm{a}$ \\
\hline $\mathrm{Na}_{2} \mathrm{SiO}_{3}+\mathrm{NaCl}$ & $1 / 100$ & $67,589 \pm 2,02 b$ & $34,276 \pm 0,57 b$ \\
\hline \multicolumn{4}{|c|}{ FEIJÃO } \\
\hline \multicolumn{4}{|l|}{ Foliar } \\
\hline $\mathrm{Na}_{2} \mathrm{SiO}_{3}+\mathrm{NaCl}$ & $0 / 0$ & $63,460 \pm 2,59 b$ & $23,155 \pm 0,62 b$ \\
\hline $\mathrm{Na}_{2} \mathrm{SiO}_{3}+\mathrm{NaCl}$ & $1 / 0$ & $62,990 \pm 2,56 \mathrm{~b}$ & $21,090 \pm 1,74 b$ \\
\hline $\mathrm{Na}_{2} \mathrm{SiO}_{3}+\mathrm{NaCl}$ & $0 / 100$ & $88,596 \pm 0,73 \mathrm{a}$ & $37,745 \pm 1,99 a$ \\
\hline $\mathrm{Na}_{2} \mathrm{SiO}_{3}+\mathrm{NaCl}$ & $1 / 100$ & $89,534 \pm 1,09 \mathrm{a}$ & $38,276 \pm 1,55 \mathrm{a}$ \\
\hline \multicolumn{4}{|l|}{ Direta } \\
\hline $\mathrm{Na}_{2} \mathrm{SiO}_{3}+\mathrm{NaCl}$ & $0 / 0$ & $76,660 \pm 1,52 b$ & $32,816 \pm 0,25 b$ \\
\hline $\mathrm{Na}_{2} \mathrm{SiO}_{3}+\mathrm{NaCl}$ & $1 / 0$ & $75,550 \pm 1,35 b$ & $31,140 \pm 0,41 b$ \\
\hline $\mathrm{Na}_{2} \mathrm{SiO}_{3}+\mathrm{NaCl}$ & $0 / 100$ & $86,987 \pm 0,43 a$ & $49,137 \pm 0,53 \mathrm{a}$ \\
\hline $\mathrm{Na}_{2} \mathrm{SiO}_{3}+\mathrm{NaCl}$ & $1 / 100$ & $84,072 \pm 2,19 \mathrm{a}$ & $48,670 \pm 0,68 \mathrm{a}$ \\
\hline
\end{tabular}

Letras iguais na mesma coluna não representam diferenças significativas pelo Teste de Tukey ao nível de significância de 5\%

nutriente nas folhas dessas plantas. Para esses autores, o fato de o teor de Si não aumentar com a sua aplicação significa que as plantas não o absorveram ou, pelo menos, não o translocaram. Portanto, novos experimentos devem ser realizados para explorar estas possibilidades.

\section{Conclusão}

O silício, na dose utilizada e aplicado diretamente na solução nutritiva, atenua os efeitos negativos, no crescimento, promovidos pelo $\mathrm{NaCl}$ em plântulas de milho, mas não exerce efeitos positivos na cultura do feijão-de-corda.

\section{Agradecimentos}

Os autores agradecem o apoio do Instituto Nacional de Ciência e Tecnologia em Salinidade (INCTSal/CNPq), da Coordenação de Aperfeiçoamento de Pessoal de Nível Superior (CAPES) e do Programa Institucional de Bolsas de Iniciação Científica (PIBIC) pelo apoio financeiro e bolsas concedidas.

\section{Referências}

AHMAD, R.; ZAHEER, S.; ISMAIL, S. Role of silicon in salt tolerance of wheat (Tritium aestivum L.). Plant Science, v. 85, n. 01, p. 43-50, 1992. 
AL-AGHABARY, K.; ZHU, Z.; SHI, Q. Influence of silicon supply on chlorophyll content, chlorophyll fluorescence, and antioxidative enzyme activities in tomato plants under salt stress. Journal of Plant Nutrition, v. 12, n. 01, p. 2101-2115, 2004.

ALVES, F. A. L. et al. Mecanismos fisiológicos envolvidos com a diminuição de $\mathrm{K}^{+}$em raízes de cajueiro causada por $\mathrm{NaCl}$. Revista Ciência Agronômica, v. 40, n. 04, p. 588-595, 2009.

BRADBURY, M.; AHMAD, R. The effect of silicon on the growth of Prosopis juliflora growing in saline soil. Plant and Soil, v. 125, n. 01, p. 71-74, 1990.

DANTAS, J. A. et al. Efeito da salinidade sobre o crescimento e composição mineral de seis clones de Pennisetum. Revista Ciência Agronômica, v. 37, n. 01, p. 97-101, 2006.

DEBOUBA, M. et al. $\mathrm{NaCl}$ stress effects on enzymes involved in nitrogen assimilation pathway in tomato Lycopersicon esculentum seedlings. Journal of Plant Physiology, v. 163, n. 12, p. 1247-1258, 2006.

EPSTEIN, E. Silicon. Annual Review of Plant Physiology and Plant Molecular Biology, v. 50, n. 01, p. 641-664, 1999.

FRANZOTE, B. P. et al. Aplicação foliar de silício em feijoeiro comum. In: CONGRESSO NACIONAL DE PESQUISAS SOBRE FEIJÃO, 8., 2005, Santo Antônio de Goiás. Anais eletrônicos... Santo Antônio de Goiás: Embrapa-CNPAF, 2005. Disponível em: <http://www.cnpaf. embrapa.br/conafe/conafeviii/pdf/conafe2005-0087.pdf>. Acesso em: 25 nov. 2010.

FREITAS, L. B. et al. Efeito da adubação foliar com silício na cultura do milho. In: REUNIÃO BRASILEIRA DE FERTILIDADE DO SOLO E NUTRIÇÃO DE PLANTASFERTBIO 2008, 17., 2008, Londrina. Anais eletrônicos... Londrina: FERTBIO 2008, 2008, Disponível em:<http://www. fertbio2008.com.br Acesso em: 25 nov. 2010.

HOAGLAND, D. R.; ARNON, D. I. The water-culture method for growing plants without soil. Berkeley: University of California, College of Agriculture, Californian Agricultural Experimental Station, 1950. 39 p. (Bulletin 347).

HODSON, M. J. et al. Phylogenetic variation in the silicon composition of plants. Annals of Botany, v. 96, n. 01, p. 1027-1046, 2005.

LACERDA, C. F. Interação salinidade x nutrição mineral. In: NOGUEIRA, R.J.C.; ARAÚJO, E. L.; WILLADINO, L. G; CAVALCANTE, U. Estresses ambientais: Danos e benefícios em plantas. Recife: Universidade Federal Rural de Pernambuco, 2005. cap 2. p. 127-137.
MA, J. F.; MIYAKE, Y.; TAKAHASHI, E. Silicon as a beneficial element for crop plant. In: Datnoff, L. E.; Korndörfer, G. H.; Snyder, G. (ed.). Silicon in agriculture. New York: Elsevier Science, 2001. cap. 05, p. 17-39.

MA, J. F.; TAKAHASHI, E. Soil, fertilizer, and plant silicon research in Japan. 1 ed. Amsterdam: Elsevier Science, 2002. 503p.

MARSCHNER, H. Mineral nutrition of higher plants. 2. ed. London: Academic Press, 1995. 889 p.

MIRANDA, J. R. P. et al.Silício e cloreto de sódio na nutrição mineral e produção de matéria seca de plantas de moringa (Moringa oleifera LAM.). Revista Brasileira de Ciências do Solo, v. 26, n. 01, p. 957-965, 2002.

MITANI, N.; YAMAJI, N.; MA, J. F. Identification of maize silicon influx transporters. Plant and Cell Physiology, v. 50, n. 01, p. 5-12, 2009.

MUNNS, R. Comparative physiology of salt and water stress. Plant, Cell and Environmental, v. 25, p. 239-250, 2002.

MUNNS, R.; TESTER, M. Mechanisms of Salinity Tolerance. Annual Review of Plant Biology, v. 59, n.01, p. 651-681, 2008.

OLIVEIRA, L. A. Silício em plantas de feijão e arroz: absorção, transporte, redistribuição e tolerância ao cádmio. 2009. 157 f. Tese (Doutorado em Energia Nuclear na Agricultura e no Ambiente) - Universidade de São Paulo, São Paulo.

PARIDA, A. K.; DAS, A. B. Effects of $\mathrm{NaCl}$ stress on nitrogen and phosphorous metabolism in a true mangrove Bruguiera parviflora grown under hydroponic culture. Journal of Plant Physiology, v. 161, n. 08, p. 921-928, 2004.

SILVEIRA, L. S. et al. Teores foliares de macro e micronutrientes no feijoeiro cv BRS-MG Talismã em função da aplicação foliar de silício inverno In: CONGRESSO NACIONAL DE PESQUISAS SOBRE FEIJÃO, 8., Santo Antônio de Goiás. Anais eletrônicos... Santo Antônio de Goiás: Embrapa-CNPAF, 2005. Disponível em: <http:// www.cnpaf.embrapa.br/conafe/conafeviii/pdf/conafe20050075.pdf $>$. Acesso em: 25 nov. 2010.

TAHIR, M. A. et al. Beneficial effects of silicon in wheat (Triticum aestivum L.) under salinity stress. Pakistan Journal of Botany, n.38, v. 05, p. 1715-1722, 2006.

TAKAHASHI, E.; MA, J. F.; MIYAKE, Y. The possibility of silicon as an essential element for higher plants. Comments on Agricultural and Food Chemistry, n. 02, p. 99-122. 1990. 